\title{
THE PALEOMAGNETISM OF THE TALCHIR SERIES OF THE LOWER GONDWANA SYSTEM, CENTRAL INDIA
}

\author{
H. WENSINK and C. T. KLOOTWIJK \\ Geological Institute, State University Utrecht, \\ Oude Gracht 320, Utrecht, The Netherlands
}

Received 14 May 1968

\begin{abstract}
Oriented samples were collected from two localities in the Upper Carboniferous Talchir Series in Central India. The material from one locality - slightly disturbed, almost unconsolidated, laminated sediments near Nagpur - revealed a stable direction of magnetization after a partial demagnetization in alternating fields. The magnetic behaviour of the samples after treatment with AC magnetic fields is discussed. The mean direction of magnetization of a selected number of 23 samples is $D=66.1^{\circ}$ and $I=+59.2^{\circ}$ (pole position $31.5^{\circ} \mathrm{S}, 45.7^{\circ} \mathrm{W}, \delta p=3.2^{\circ}$ and $\delta \mathrm{m}=2.6^{\circ}$ ). The walue of the mean inclination implies that the paleolatitude of the Nagpur district was about $40^{\circ} \mathrm{S}$ during Upper Carboniferous times. It is argued that this latitude is not contrary to the glacial conditions prevailing at the time of the deposition of the sediments.
\end{abstract}

\section{INTRODUCTION}

This study deals with the paleomagnetism of a series of the lowermost Gondwana deposits of the Central Indian peninsula. The Gondwana sediments, ranging in age from Upper Carboniferous to Middle Cretaceous, cover either Precambrium basement rocks or late-Precambrium sediments. A younger main unit - locally overlying the Gondwanas - is formed by the Deccan Traps, a series of plateau-basalts extruding at the transition-period from Mesozoic and Tertiary (fig. 1).

On the Indian subcontinent the Gondwanas are mainly preserved in a number of tectonic depressions, which are bounded by NW-SE running faults. The non-marine sediments with a total thickness of $3000 \mathrm{~m}$ are subdivided into the Lower and Upper Gondwana Systems * and these Systems are subdivided into a number of Series $[1,2]$.

Oriented samples were collected in the Talchir Series, which is the lowest member of the Lower Gondwana System. This Series consists of fine-grained silty

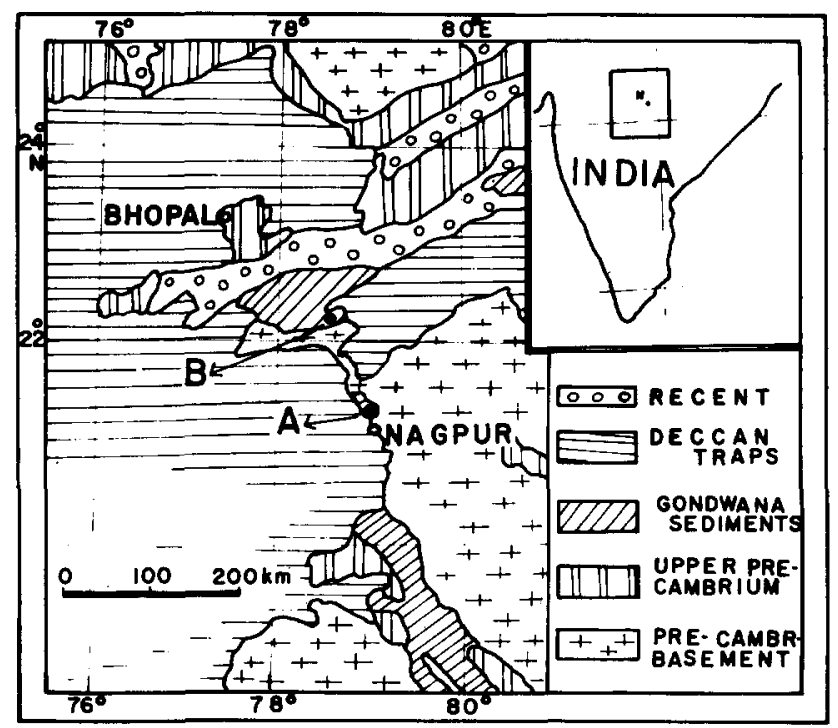

* Wadia subdivides the Gondwana sediments into three Systems.

Fig. 1. Geological map of the area around Nagpur showing sampling sites. 
shales, mudstones and fine-grained, soft sandstones. We often find boulderbed(s) intercalated in the sediments, generally towards the base of the series.

These beds, the Talchir boulder beds, are of glacial origin, and form the Indian representatives of deposits formed during the Permo-Carboniferous ice-ages; the glaciation in India, however, was of a very short duration. The Talchir glacial deposits are less extensive than the glacial sediments in Africa: the Dwyka Tillite Formation. It is also impossible to compare the glacial deposits in India with the repeated occurrences of glacial conditions prevailing in Australia during Upper Carboniferous-Permian times.

The Talchir deposits are very poor in fossils. Locally the overlying sediments of the Damuda Series have yielded faunas that are comparable to the faunas of the Australian Lower Marine Series of Permian age. In general, an Upper-Carboniferous age is assigned to the Talchir Series [3].

\section{SAMPLING AREAS}

Samples were collected at two different localities: in an isolated Gondwana outcrop near Nagpur ( $A$ in fig. 1) and in the northern part of the Satpura area (B in fig. 1).

The locality near Nagpur is situated about 3 miles north from the city in a small stream just east of the highway Nagpur-Chchindwara. Here, reddish-brown, almost unconsolidated sediments are exposed, which consist of a rapid alternation of sand and clay lamellae; the individual sandy beds are 1-3 mm thick, the clayish beds are up to $1 \mathrm{~cm}$ thick. The sediments are slightly disturbed. In their very vicinity outcrops of Precambrium gneisses are found, which, however, do not show any contact with the overlying Talchir Series. In this locality boulder beds are exposed too. These beds contain hard, well-rounded, sometimes even polished boulders of quartz, gneiss, quartsite and limestone, which lie completely unsorted in a sandyclayish groundmass. Reworked fragments of the laminated sediments occur both at the base of the boulder beds and as pockets within these beds. Though most of the finer material seems to have been washed out, the glacial character of the boulder beds is unquestionable. The irregular deformations of the laminated sediments can best be explained as being the result of ice-pushing.
Drilling was unsuccessful because of the unconsolidated character of the sediments. About 30 oriented handsamples were taken, with an average volume of $150 \mathrm{~cm}^{3}$.

The second sampling locality is situated near the Piparia railway station in the northern Satpura area, Hosangabad district. From here towards the north a thick pile of slightly $\mathrm{N}$ dipping Gondwana sediments is exposed. The Talchir Series near Piparia consists of variegated shales and fine sandstones. The sediments are heavily intruded by sills and dikes of the Deccan volcanic suite. Another 30 handsamples were collected here.

\section{TREATMENT IN THE LABORATORY}

The samples were studied in the Paleomagnetic Laboratory of Utrecht University. All specimens were embedded in an oriented position in cubes of paraffin with sides of $10 \mathrm{~cm}$. The measurements were carried out with sensitive astatic magnetometers. A few pilot samples were progressively demagnetized in alternating magnetic fields, up to a maximum peak value of $\mathbf{3 0 0 0}$ oersted. The remaining samples were subjected to progressive demagnetizations in fields with a maximum value of 500 oersted. Different procedures were applied in order to understand the behaviour of the rocks during demagnetization (see next section).

Unfortunately, heating experiments were not successful. As the Talchir sediments were not suitable for drilling, only irregular specimens could be placed in the furnace; when being heated they soon disintegrated.

\section{DEMAGNETIZATION PROCEDURES WITH ALTERNATING MAGNETIC FIELDS (AC)}

The change in both the intensity and the direction of the remanent magnetization of a rock sample during progressive demagnetization can be illustrated by means of a series of vectors. Each individual vector represents both the direction and magnitude of the magnetization after a demagnetization step. The vectors are projected in a rectangular axis system on a horizontal plane as well as on a vertical plane. The endpoints of the successive vectors are connected. An example is given in fig. 2. Here dots denote the 


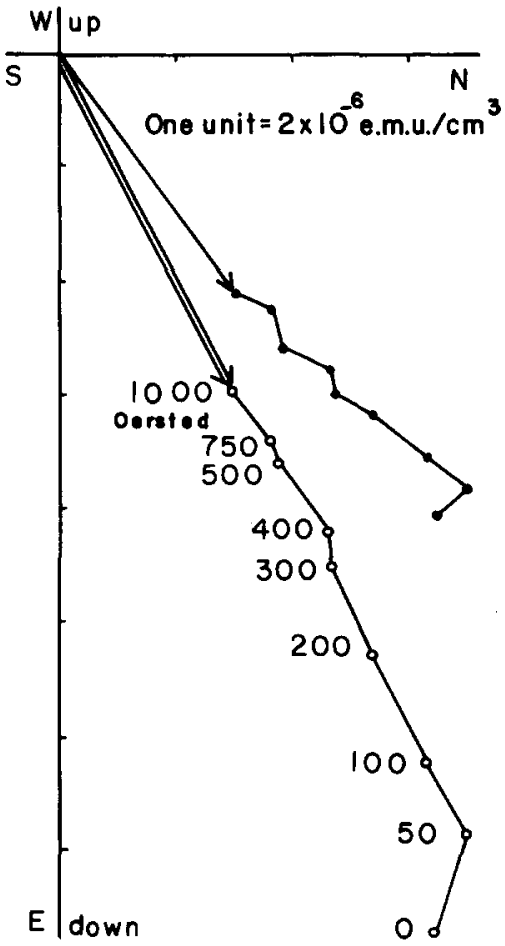

Fig. 2. Demagnetization diagram of a Talchir sample. For explanation see text.

projections on the horizontal plane to which the N-S and $\mathrm{E}-\mathrm{W}$ axes refer; open circles denote the projections on a vertical plane to which the vertical and $\mathrm{N}$-S axes refer. After treatment in an alternating magnetic field of 50 oersted peak value the resultant magnetization vector changes during the further demagnetization along a straight line which is directed towards the centre of the coordinate system. After treatment in a 50 oersted field the remaining magnetization of this sample apparently consists of one single component that may represent the original magnetization [4].

The successive endpoints of the vectors, however, never formed completely straight lines as they are supposed to do in case of one single magnetization. For this reason a more extensive procedure of demagnetization was applied.

Usually, at each step of a progressive demagnetization, the sample is treated in three successive positions - e.g. according to the vertical (V), the N-S and the $\mathrm{E}-\mathrm{W}$ directions respectively - parallel to the axis of the demagnetization coil. Then the sample is measured on the astatic magnetometer.

Another method is to demagnetize the sample along one of its axes, after which the sample is measured. With the same strength of the AC field this way of performing is also applied to the demagnetization along the remaining axes of the sample. This whole procedure is repeated at the next step of demagnetization.

An example of the latter procedure is given in fig. 3 . Here the intensities of remanent magnetization along the three axes of a sample are plotted against the oersted peak values of the alternating magnetic field. This procedure was applied to fields of 300,400 and 500 oersted. In fig. 3 it can be seen that through successive demagnetization of the three components of the sample in an alternating magnetic field of the same force, the remanent magnetization shows variations. These variations are stronger for the $B$ and $C$ components than they are for the A component. This is observed regularly with samples treated in this way.

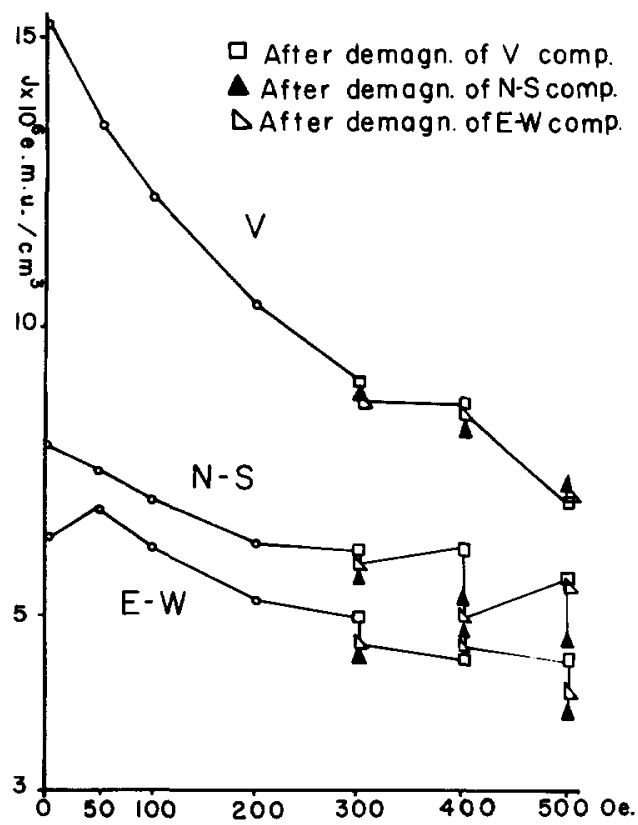

Fig. 3. Diagram showing the change of the intensity of magnetization during progressive $\mathrm{AC}$ demagnetization. At the steps with 300,400 , and 500 oersted a special method has been applied (see text). 


\section{ANISOTROPY OF THE SEDIMENTS}

The AC demagnetization of the laminated Talchir sediments has shown that during this treatment the magnetic behaviour of the rock is anisotropical. The magnetic properties in the B-C plane, i.e. the plane of deposition, are different from what they are in a vertical plane.

The method described by As [5] was used to present qualitative data for the anisotropy of the susceptibility of the Talchir sediments. The susceptibility in the vertical direction has a lower value with respect to the values found in the N-S and E-W directions, which correspond to the bedding plane.

For the three main directions the mean values of the susceptibilities were computed from 14 samples. The values are given normalized to the vertical direction:

$\begin{array}{ccc}\text { Vertical } & \text { N-S } & \text { E-W } \\ 1.00 & 1.10 & 1.04\end{array}$

Thus an excess of susceptibility of up to $10 \%$ was found in the horizontal plane with regard to its normal. These results are comparable to those mentioned by Granar [6] who studied the anisotropy of the susceptibility of varves in Sweden which had an excess of susceptibility in the horizontal plane of 10 to $20 \%$.

\section{RESULTS}

The samples collected near Piparia (locality B in fig. 1) did not reveal a reliable, original direction of magnetization. The results will not be further discussed.

The Talchir sediments from the Nagpur area, however, - when subjected to alternating field demagnetization - exhibit a stable direction of magnetization. The mean direction is significantly different from the direction of the earth's present field at Nagpur.

The slightly deformed Talchir sediments enable us to apply the unfolding test [7]. When the magnetization of the sediments is prior to the tectonic deformation, a narrower cluster of the directions of magnetization of the individual samples can be expected after tectonic correction.

In table 1 the mean values of the directions of the NRM as well as that of the magnetizations after de-
Table 1

Mean directions of magnetization for the Talchir sediments.

\begin{tabular}{llccccc}
\hline$N$ & Treatment & $D$ & $I$ & $R$ & $k$ & $\alpha_{95}$ \\
23 & NRM & $57.4^{\circ}$ & $+51.0^{\circ}$ & 22.65 & 63.0 & $3.8^{\circ}$ \\
23 & 300 Oe & $53.7^{\circ}$ & $+45.6^{\circ}$ & 22.6 & 55.2 & $4.1^{\circ}$ \\
23 & $\begin{array}{l}\text { NRM with } \\
\text { tectonic } \\
\text { correction }\end{array}$ & $73.2^{\circ}$ & $+63.7^{\circ}$ & 22.75 & 86.3 & $3.3^{\circ}$ \\
& $\begin{array}{l}300 \text { Oe with } \\
\text { tectonic } \\
\text { correction }\end{array}$ & $66.1^{\circ}$ & $+59.2^{\circ}$ & 22.8 & 109.4 & 2.90 \\
\hline
\end{tabular}

$N$ is the number of samples included in the analysis; $R$ is the length of the resultant of the $N$ unit vectors and $D$ and $I$ are the declination and inclination of its direction; $k=(N-1) /(N-R)$, the best estimate of Fisher's dispersion parameter; $\alpha_{95}$ is the semiangle of the cone of $95 \%$ confidence.

magnetization in $300 \mathrm{Oe}$ are listed both before and after tectonic correction*. The consistency of the measurements of the NRM of individual samples had not improved after partial demagnetization without applying tectonic correction. After the application of tectonic correction, however, a narrower cluster of the directions of the NRM was obtained; the consistency further improved after demagnetization of the samples in an alternating magnetic field of 300 oersted peak value.

The deformation of the laminated, peri-glacial Talchir deposits was very likely the result of a pushing of the Gondwana glaciers; this occurred soon after the sedimentation. As the directions of magnetization of individual samples of the Talchir Series show the narrowest cluster after tectonic correction, the sediments may have received their magnetization either during deposition or very soon afterwards.

Some magnetic properties of the Talchir sediments are listed in table 2. A normalized demagnetization curve is shown in fig. 4 .

Table 3 gives the pole position computed from the mean direction of magnetization of 23 samples after treatment at $300 \mathrm{Oe}$ and after tectonic correction. The paleolatitude is given too, and was calculated by means of the dipole equation $\tan \lambda=\frac{1}{2} \tan I$, where $I$ is the magnetic inclination. This would locate the Nagpur area at $40^{\circ}$ South Latitude during Upper Carbon-

* Three samples that strongly deviated in the direction of their magnetization from all other samples were rejected. Another four samples disintegrated during embedding in paraffin. 
Table 2

Mean values of magnetic properties.

\begin{tabular}{ccccc}
\hline Treatment & $J \times 10^{6} \mathrm{emu} / \mathrm{cm}^{3}$ & $Q$ & $\begin{array}{c}Q \text {-percent- } \\
\text { age }\end{array}$ & $\kappa \times 10^{6}$ \\
\hline NRM & 7.6 & 0.496 & 33 & 34 \\
$300 \mathrm{Oe}$ & 4.9 & 0.315 & 23 & - \\
\hline
\end{tabular}

$J$ is the intensity of the remanent magnetization; $Q$ is the ratio of the remanent magnetization to that induced by the present field; $Q$-percentage is $(J /(J+M)) \times 100 \%$, where $M$ is the induced magnetization; $\kappa$ is the mean susceptibility.

iferous times (fig. 5). This is, of course, a minimum value, because compaction of the sediment may lead to a lower inclination than the original one.

The value for the paleolatitude is in accordance with the glacial data available. In India the glacial epoch was single and short-lived. Moreover, in Africa, remnants of the Gondwana glaciation are found even $\mathrm{N}$ of the $40{ }^{\circ}$ paleolatitude.

The virtually latitudinal positions of India during both the Upper Carboniferous and the Upper Cretaceous [8] are presented on a map of the Indian Ocean (fig. 6), where the subcontinent has been shifted along the $800 \mathrm{E}$ meridian.

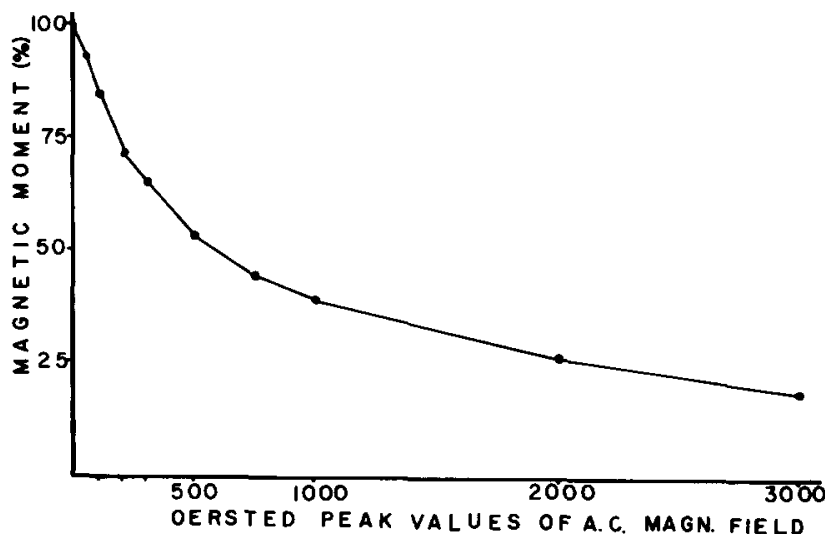

Fig. 4. Alternating-field demagnetization curve of a Talchir specimen.
Table 3

Pole position calculated from the mean direction of magnetization.

\begin{tabular}{lccccc}
\hline \multicolumn{2}{c}{ Site position } & \multicolumn{4}{c}{ Site pole } \\
\hline Lat. N & Long. E & Lat. S & Long.W & $\delta p$ & $\delta m$ \\
$21.40^{\circ}$ & $78.95^{\circ}$ & $31.5^{\circ}$ & $45.7^{\circ}$ & $3.2^{\circ}$ & $2.6^{\circ}$ \\
\hline
\end{tabular}

$\delta p$ and $\delta m$ are the semiaxes of the oval of $95 \%$ confidence for the mean pole position.

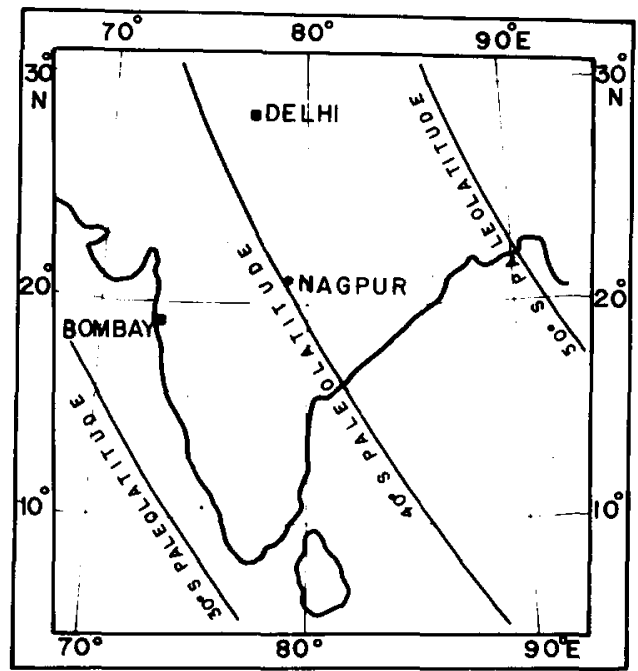

Fig. 5. The paleolatitude of India in the Upper Carboniferous.

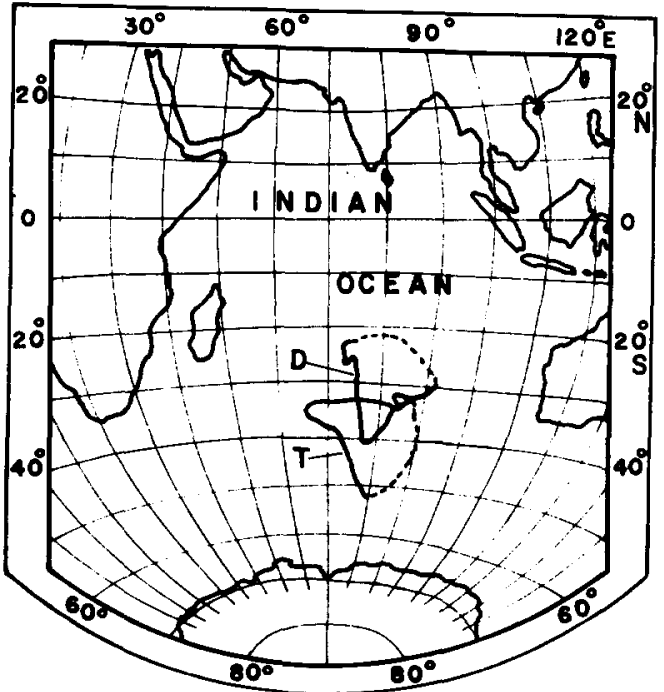

Fig. 6. Map of the Indian Ocean with the virtual positions of India during the Upper Carboniferous (T), and the Upper Cretaceous (D). 


\section{REFERENCES}

[1] D. N. Wadia, Geology of India (3rd ed.) (MacMillan, London, 1953) $532 \mathrm{pp}$.

[2] M. S. Krishnan, Geology of India and Burma (4th ed.) (Higginbothams, Madras, 1960) 604 pp.

[3] E. H. Pascoe, A manual of the Geology of India and Burma (2nd ed.), vol. II, Governm. Press, Delhi (1959).

[4] J. D. A. Zijderveld, AC demagnetization of rocks: Analysis of results, in: D. W. Collinson et al. (eds.), Methods in Faleomagnetism, Elsevier, Amsterdam (1967) p. 254.
[5] J. A. As, Measurements of anisotropy of the susceptibility with an astatic magnetometer, in: $D$. W. Collinson et al. (eds.), Methods in Paleomagnetism, Elsevier, Amsterdam (1967) p. 362.

[6] L. Granar, Magnetic measurements on Swedish varved sediments, Arkiv. Geofysik 3 (1958) 1.

[7] J. W. Graham, The stability and significance of magnetism in sedimentary rocks, J. Geophys. Res. 54 (1949) 131.

[8] E. R. Deutsch, C. Radakrishnamurty and P.W.Sahasrabudhe, Paleomagnetism of the Deccan Traps, Ann. Geophys. 15 (1959) 39. 